\title{
Optimization of Xylose yield from water hyacinth for ethanol production using Taguchi Technique
}

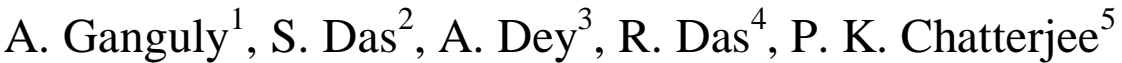 \\ 1,4,5 (Thermal Engineering Group, Central Mechanical Engineering Research Institute, Durgapur-713209, \\ India) \\ 2,3 (Department of Biotechnology, National Institute of Technology, Durgapur-713209, India)
}

\begin{abstract}
The conversion of water hyacinth to ethanol can be achieved by pretreatment, enzymatic hydrolysis and simultaneous saccharification and fermentation. The utilization of both cellulose and hemicellulosic sugars such as hexose, pentose and the like present in the hydrolysate is essential for the economical production of ethanol. Water hyacinth requires pretreatment in order to enhance the susceptibility of the biomass during hydrolysis. The present study, aims at applying a simple and reliable pretreatment process with dilute sulfuric acid hydrolysis for the conversion of water hyacinth to xylose. In this study, a systematic and robust optimization strategy was adopted to find out the optimum settings of the process parameters for enhanced production of xylose from water hyacinth using Taguchi's parameter design. From confirmation experiments, the mean value of the xylose yield corresponding to the optimum conditions was obtained as $65.03 \mathrm{mg} \mathrm{g}^{-1}$, which is close to the predicted range.
\end{abstract}

Keywords - Bioconversion, pretreatment, taguchi method, water hyacinth, xylose yield.

\subsection{Background and objective}

\section{Introduction}

For several decades, ethanol has been promoted as a promising alternative fuel for transportation. The use of fossil fuels has contributed to the build-up of carbon dioxide in the atmosphere. However, ethanol is a clean-burning fuel that makes no net contribution to global warming because the carbon dioxide produced by the combustion of ethanol is consumed by plant growth which continues the carbon cycle balance in the nature. Ethanol can be produced from inexpensive and abundant lignocellulosic biomass. It is important to look for sources of lignocellulosic biomass from which ethanol can be produced at a reasonable cost with available resources. Earlier, sugarcane bagasse, corn strover and others were used as raw materials. However it is now under strict control to ensure security of food grains.

An important alternative solution to this food security problem is the conversion of lignocellulosic materials to Ethanol. Energy security, economic security, sustainability and en vironmental benefits are the main drivers for the cellulosic ethanol industry. Water hyacinth can be utilized for this process of conversion to ethanol. Water hyacinth, Eichhornia crassipes is a monocotyledonous freshwater aquatic plant, belonging to the family Pontederiaceae. It is considered as a noxious weed in many parts of the world as it grows very fast and depletes nutrient and oxygen rapidly from water bodies, adversely affecting flora and fauna. Moreover due to high evapo-transpiration it adds to water crisis all over the places where it grows. The possibility of converting water hyacinth fuel ethanol is currently established in a number of developing countries, and can be utilised in India [1]. Production of food, fuels and chemicals from materials considered as "waste" constitutes a valuable service in the self-sustaining society might be envisioned for the future.

The biological conversion of ethanol from lignocellulosic biomass can be achieved by pretreatment, enzymatic hydrolysis and fermentation. The simultaneous saccharification and fermentation (SSF) process was first introduced in 1977. This process (SSF) plays an effective role to overcome enzyme inhibition. SSF combines enzymatic hydrolysis with ethanol fermentation to keep the concentration of glucose low. The accumulation of ethanol in the fermentor does not inhibit cellulose as much as high concentrations of glucose, so SSF is a good strategy for increasing the overall rate of cellulose to ethanol conversion [2].

Pretreatment is an essential step to improve the ethanol yield of SSF from a lignocellulosic biomass. The utilization of both cellulose and hemicellulosic sugars like hexoses, pentose and the like, present in a typical biomass hydrolysate is essential for the economical production of ethanol [3-4]. Lignocellulosic material is very resistant to enzymatic breakdown, requiring pretreatment in order to enhance the susceptibility of the biomass to the enzyme. The present study aims at applying a simple and reliable pretreatment process with dilute acid hydrolysis for the conversion of water hyacinth to xylose. The water hyacinth used in this study has a composition of $35 \%$ cellulose, $33.8 \%$ hemi-cellulose, $15.5 \%$ lignin as determined in the laboratory. Estimations of xylose which is a major fermentable sugar have been performed by colorimetric determinations. Moreover, different parameters like treatment temperature, treatment time, concentration of the medium, soaking time of 
the dried biomass have been considered and detailed studies were carried out with water hyacinth to establish the variation of xylose yield. The experiment is carried out with a loading of $2.5 \%$ (w/v). Studies on the optimization of xylose conversion with different parametric designs to achieve adequate yield is of considerable importance. In a xylose yield design, as the number of parametric variables increases the number of experiments also increases. The traditional approach for such experimental studies is to use full factorial or fractional factorial design followed by response surface modelling. However, in the case of a full factorial design the number of experiments is numerous, and it is practically not possible to carry out the experiments in majority of situations. An alternative approach for optimization is to adopt Taguchi's parameter design method based on orthogonal arrays $(\mathrm{OA})$, which is widely used in research and industrial applications. This method is economic one as fewer experiments are required to obtain the optimum levels of the process parameters. Moreover, use of this method helps to make a process/product robust against environmental conditions/sources of noise, thus improving its field performance. Precisely, parameter design technique leads to achieve high quality of a product or component at low cost. The existing literature provides limited information on the optimization for constituent materials to be used for maximizing the xylose yield using orthogonal array design.

Thus the objective of the present study is to find out the optimum conditions of the control variables for an enhanced production of xylose from lignocellulosic biomass. The experiments were designed using an $\mathrm{L}_{9}$ standard orthogonal array considering the process parameters such as temperature, concentration, treatment time, soaking time and each with three levels. Results derived from statistical analysis of the experimental data are presented, based on Taguchi's parameter design technique.

\subsection{Parameter design methodology}

Taguchi method involves the establishment of different experimental situations through orthogonal arrays $(\mathrm{OA})$ to reduce experimental errors and to enhance the efficiency and reproducibility of experiments. It helps to minimize the effects of noise factors in the process of optimization and leads to a dynamic or robust experimental design [5]. Taguchi's parameter design method is a powerful tool for optimizing the performance characteristic of a product / process. The aim of a parameter design experiment is to identify and design the settings of the process parameters that optimize the chosen quality characteristic and are least sensitive to noise factors. In the present study the goal is to evaluate the effects of process variables on the performance measure and the optimum combination of control factors that would maximize the xylose yield (measured in the laboratory), which is chosen as the quality characteristic. The cause-and-effect diagram illustrating the possible effects of the various factors on the production/yield of xylose is shown in Fig. 1.

Selection of control factors and their levels were made on the basis of some preliminary trial experiments conducted in the laboratory and also from literature review on the subject.

These parameters are observed to have a critical effect on the overall yield of xylose from lignocellulosic biomass. All the variables were investigated within the feasible range so that the variation inherent in the process does not mask the factor effect. Operational factors affect the breakdown of lignocellulosic biomass and consequently the xylose yield. In this study, temperature, concentration, treatment time, soaking time was considered as the four important factors for degradation of lignocellulosic biomass and production of xylose [6-8]. All the variables were investigated at three widely spaced levels as shown in Table 1. The choice of the three levels has been made to account for the non linear variation of the parametric effects on the quality characteristic.

\subsection{Design of experiment}

The experiments were designed based on the orthogonal array technique. An orthogonal array is a fractional factorial design with pair wise balancing property. Using orthogonal array design the effects of multiple process variables on the performance characteristic can be estimated simultaneously while minimizing the number of test runs. An $\mathrm{L}_{9}\left(3^{4}\right)$ standard orthogonal array [9] as shown in Table 2a was employed for the present investigation. This array is most suitable to provide the minimum degrees of freedom as $9[=1+4 \mathrm{x}$ (3-1)] required for the experimental exploration. Table $2 \mathrm{~b}$, represents the layout of the experimental design, which has been obtained by assigning the selected factors and their levels to appropriate columns of $\mathrm{L}_{9}$ orthogonal array. This array has 9 rows and 4 columns and each row represents a trial condition while each column accommodates a specific process parameter. Moreover, the notation $3^{4}$ implies that at most 4 factors, each at 3 levels can be investigated using this OA and their main effects can be estimated provided all other interactions are negligible which is assumed in the present case. The numbers in each column indicate the levels of specific factors (A, B, C and D). However, while conducting the experiments the test runs have been randomly made to avoid the unidentified noise sources, which are not considered but could have an adverse impact on the response characteristic. 


\subsection{Preparation of water hyacinth}

\section{Materials and Experimental Procedure}

Fresh water hyacinth with long stem was collected from a natural pond. The water hyacinth was thoroughly washed several times with tap water to remove adhering dirt, chopped into small pieces of size 1-2 $\mathrm{cm}$ (approx), and further grounded to even smaller particles of size 1-2 $\mathrm{mm}$ (approx), and finally dried in a hot air oven at $106^{\circ} \mathrm{C}$ for 6 hours. The dried material was stored at room temperature until used. The dried water hyacinth was studied under a Magnus make compound microscope for its cell structure.

\subsection{Preparation of hemicellulose acid hydrolysate}

$50 \mathrm{mg}$ of dried water hyacinth was mixed with $1 \%, 2 \%, 3 \%, 4 \%$ and $5 \%$ concentration (C) of sulfuric acid to a final volume of $20 \mathrm{ml}$. The soaking times (Ts) of the mixtures were $15 \mathrm{~min}, 30 \mathrm{~min}, 45$ min and $60 \mathrm{~min}$. The acid hydrolysis reactions were carried out in the temperature (T) range of $40{ }^{\circ} \mathrm{C}$ to $150{ }^{\circ} \mathrm{C}$ for a treatment time $\left(\mathrm{T}_{\mathrm{t}}\right)$ range of $2-10 \mathrm{~min}$ after which the hydrolysate was cooled down to room temperature. The hydrolysate was filtered using watman paper 1 to remove the unhydrolysed material. The filtrate was collected and subjected to analyze the xylose content.

\subsection{Determination of xylose content by phloroglucinol assay}

Xylose yield (Y) was determined using the Phloroglucinol assay [10-11] with the hydrolysate obtained from acid hydrolysis.

Xylose content was determined using the Phloroglucinol. Briefly, the colour reagent consisting of $0.5 \mathrm{gm}$ of phloroglucinol, $100 \mathrm{ml}$ of glacial acetic acid, and $10 \mathrm{ml}$ of conc. $\mathrm{HCl}$ were freshly prepared and used within 4 days. Stock standard xylose $\left(10 \mathrm{gm} \mathrm{l}^{-1}\right)$ was prepared by dissolving D-xylose powder in saturated benzoic acid and used for preparation of the calibration curve. To the procedure herein, two hundred micro liters of sample was mixed with $5 \mathrm{ml}$ colour reagent and subsequently heated at $100{ }^{\circ} \mathrm{C}$ for $4 \mathrm{~min}$. The reaction was rapidly cooled down to room temperature using cold water bath. The absorbance of the final solution was studied in a Colorimeter at a wavelength of $570 \mathrm{~nm}$.

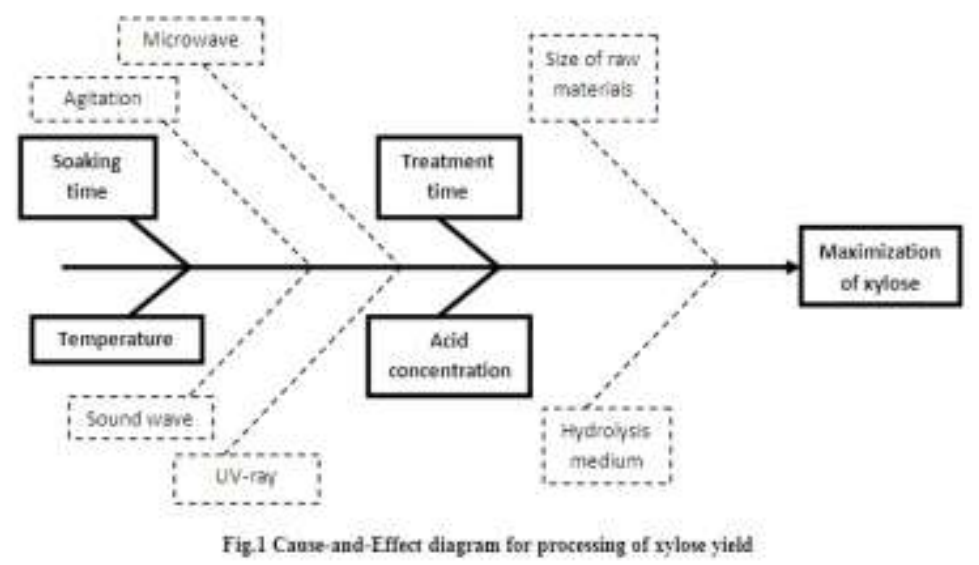

Table 1 Process parameters and their levels

\begin{tabular}{lllll}
\hline \multicolumn{5}{c}{ Table 1 Process parameters and their levels } \\
Factors & $\begin{array}{l}\text { Coded } \\
\text { Factors }\end{array}$ & Level-1 & Level-2 & Level-3 \\
\hline & & & & \\
Temperature $\left({ }^{\circ} \mathrm{C}\right)$ & $\mathrm{A}$ & 90 & 130 & 150 \\
Concentration $(\%)$ & $\mathrm{B}$ & 1 & 3 & 5 \\
Treatment Time (min) & $\mathrm{C}$ & 2 & 5 & 10 \\
Soaking Time (min) & $\mathrm{D}$ & 30 & 45 & 60 \\
& & & & \\
\hline
\end{tabular}

Table 2a L9 $\left(3^{4}\right)$ Standard orthogonal array

\begin{tabular}{lllll}
\hline Experiment no. & Factor A & Factor B & Factor C & Factor D \\
\hline 1 & 1 & 1 & 1 & 1 \\
2 & 1 & 2 & 2 & 2 \\
3 & 1 & 3 & 3 & 3 \\
4 & 2 & 1 & 2 & 3
\end{tabular}




\begin{tabular}{lllll}
\hline 5 & 2 & 2 & 3 & 1 \\
6 & 2 & 3 & 1 & 2 \\
7 & 3 & 1 & 3 & 2 \\
8 & 3 & 2 & 1 & 3 \\
9 & 3 & 3 & 2 & 1 \\
\hline
\end{tabular}

Table 2b Layout of Experimental Design $\left(3^{4}\right)$

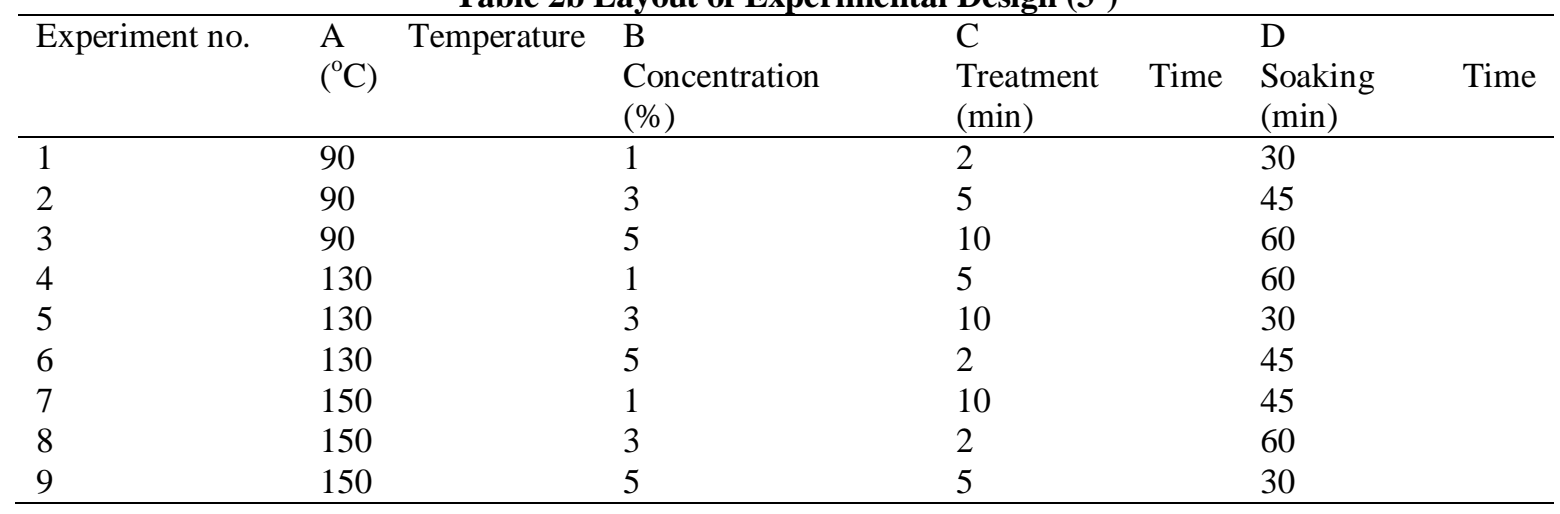

\section{Analysis, Results and Discussion}

\subsection{Optimization of parameters}

The experimental data obtained corresponding to determination of xylose content was processed using Qualitek-4 software (Nutec Inc, MI, and USA). Three replicated readings are recorded for each experimental condition as shown in Table 3. Conventionally, data from a designed experiment are used to analyze the mean response function.

In Taguchi technique the variation of the response is also examined using an appropriately chosen Signal-to-Noise $(\mathrm{S} / \mathrm{N})$ ratio. According to Taguchi method the term 'signal' represents the undesirable value (mean) and the term 'noise' represents the desirable value (standard deviation) for the output characteristic [9]. The $\mathrm{S} / \mathrm{N}$ ratios, derived from the quadratic loss function, are expressed on a decibel $(\mathrm{dB})$ scale.

Generally three standard S/N equations are widely used to classify the response function as: 'larger the better', 'smaller - the better, or 'nominal - the best'. However, regardless of the type of response function, a larger $\mathrm{S} / \mathrm{N}$ ratio is always desirable.

Table 3 Results for xylose yield and signal-to-noise ratio

\begin{tabular}{|c|c|c|c|c|c|}
\hline \multirow[t]{2}{*}{ Experiment No. } & \multicolumn{4}{|c|}{ Xylose Yield (mg) } & \multirow{2}{*}{$\begin{array}{l}\text { S/N Ratio } \\
\text { (dB) }\end{array}$} \\
\hline & Reading 1 & Reading 2 & Reading 3 & Mean & \\
\hline 1 & 24 & 26.15 & 22.23 & 24.126 & 27.592 \\
\hline 2 & 31.2 & 32.09 & 31.02 & 31.436 & 29.945 \\
\hline 3 & 44.02 & 41.52 & 46.85 & 44.13 & 32.863 \\
\hline 4 & 31.2 & 33.29 & 29.42 & 31.303 & 29.878 \\
\hline 5 & 62.57 & 61.28 & 64.02 & 62.623 & 35.93 \\
\hline 6 & 33.8 & 34.02 & 33.1 & 33.64 & 30.535 \\
\hline 7 & 36.4 & 38.01 & 34.98 & 36.463 & 31.222 \\
\hline 8 & 28.8 & 30.12 & 27.59 & 28.836 & 29.182 \\
\hline
\end{tabular}




$\begin{array}{llllll}9 & 43.2 & 41.11 & 45.8 & 43.37 & 32.718\end{array}$

In the present study, xylose yield (Y) is a 'larger the better' type of quality characteristic since the goal is to maximize the yield. The standard $\mathrm{S} / \mathrm{N}$ ratio computing formula for this type of response is [9].

$$
(S / N)_{i}=-10 \log \left[\frac{1}{n} \sum_{j=i}^{n} \frac{1}{Y_{i j^{2}}}\right]
$$

Where ' $\mathrm{i}$ ' is the number of a trial; $\mathrm{Y}_{\mathrm{ij}}$ is the measured value of quality characteristic corresponding to $\mathrm{i}^{\text {th }}$ trial and the $\mathrm{j}^{\text {th }}$ repetition; ' $\mathrm{n}$ ' is the number of replications for the experimental combination. Signal-to-noise ratios are computed using equation (1) for each of the nine experimental conditions and are reported in Table 3 Since the experimental design is orthogonal; the factor effects can be separated out in terms of the mean response. The average $\mathrm{S} / \mathrm{N}$ ratio for each parameter level is calculated by averaging all $\mathrm{S} / \mathrm{N}$ ratios obtained when the parameter is maintained at that level. Table 4 shows the average $\mathrm{S} / \mathrm{N}$ ratios for different parameter levels along with the relative difference.

Table 4 Average S/N Ratios for different process parameters

\begin{tabular}{|c|c|c|c|c|c|}
\hline $\begin{array}{l}\text { Sl. } \\
\text { No. }\end{array}$ & Factors & $\begin{array}{l}\text { Level } 1 \\
\left(\mathrm{~L}_{1}\right)\end{array}$ & $\begin{array}{l}\text { Level } 2 \\
\left(\mathrm{~L}_{2}\right)\end{array}$ & $\begin{array}{l}\begin{array}{l}\text { Level } 3 \\
\left(\mathrm{~L}_{3}\right)\end{array} \\
\end{array}$ & $\begin{array}{l}\text { Relative } \\
\text { Difference }\end{array}$ \\
\hline 1 & $\begin{array}{l}\text { Temperature } \\
\left({ }^{\circ} \mathrm{C}\right)\end{array}$ & 30.133 & 32.114 & 31.04 & $\begin{array}{l}1.981 \\
\left(\mathrm{~L}_{2}-\mathrm{L}_{1}\right)\end{array}$ \\
\hline 2 & Concentration (\%) & 29.564 & 31.686 & 32.038 & $\begin{array}{l}2.474 \\
\left(\mathrm{~L}_{3}-\mathrm{L}_{1}\right)\end{array}$ \\
\hline 3 & Treatment Time (min) & 29.103 & 30.847 & 33.338 & $\begin{array}{l}4.235 \\
\left(\mathrm{~L}_{3}-\mathrm{L}_{1}\right)\end{array}$ \\
\hline 4 & Soaking Time (min) & 32.08 & 30.567 & 30.641 & $\begin{array}{l}1.513 \\
\left(\mathrm{~L}_{1}-\mathrm{L}_{2}\right)\end{array}$ \\
\hline
\end{tabular}

The average values of signal-to-noise ratios of the four control factors at each of the levels are shown in Fig. 2 and from which the levels corresponding to the highest $\mathrm{S} / \mathrm{N}$ ratio values are chosen for each parameter representing the optimum condition. Here, the optimum condition is corresponding to the maximization of the xylose production.

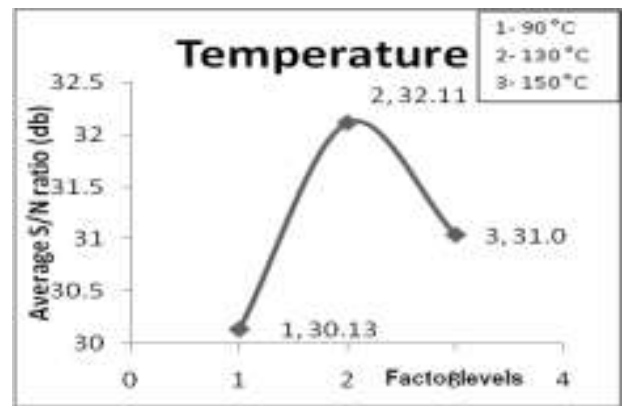

Temperature (Fig. 2a)

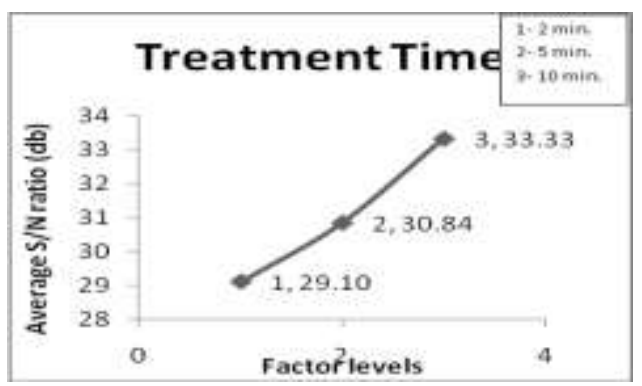

Treatment Time (Fig. 2c)

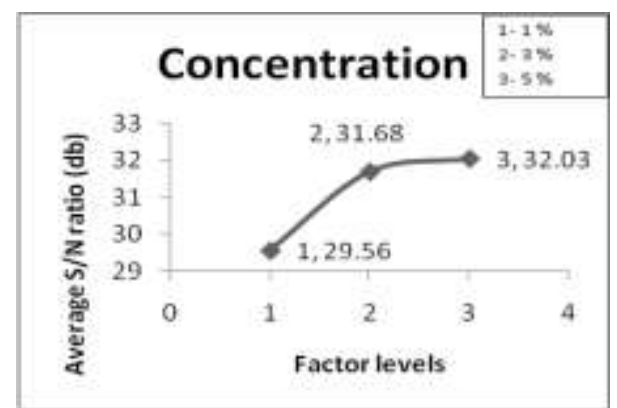

Concentration (Fig. 2b)

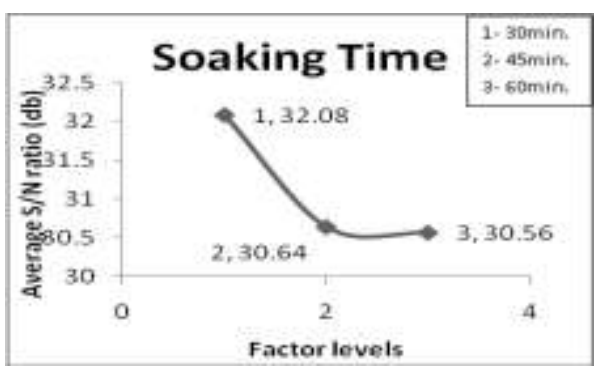

Soaking Time (Fig. 2d)

Fig. 2 Effects of process parameters on Average $\mathrm{S} / \mathrm{N}$ ratio 
It is to be noted that the $\mathrm{S} / \mathrm{N}$ ratio indicates the degree of predictable performance of a product or process in the presence of noise factors. As shown in Table 4 and Fig. 2, treatment time is a dominant parameter on the xylose yield followed by concentration. The temperature and soaking time had relatively lower effects on the xylose yield.

Fig. 2a shows the effect of temperature on the response function. A higher yield of xylose was found with subsequent increase of temperature up to level 2. But further increase of temperature (level 3) decreased the yield. Such variation may be due to the degradation of xylose into furfural, hydroxyl methyl furfurals and other acid derivatives.

The influence of concentration on xylose yield is depicted in Fig. 2b. Subsequent increase of concentration up to level 3 resulted in a higher yield. This may be due to the fact that hemi-cellulose which is heterogeneous polysaccharides has weak ester linkages. With the increase in the acid concentration up to level-3 those bonds are weakened and the xylose present in the hemi-cellulose is hydrolyzed and brought in the solution.

Fig. $2 \mathrm{c}$ shows the influence of treatment time on xylose production. Maximum yield was noticed at the level 3 of treatment time. This may be reasoned due to the fact that with the increase of treatment time the degradation of hemi-cellulose was more effectively possible which led to the weakening of the heterogeneous bonds present in hemi-cellulose leading to hydrolysis of xylose into the solution.

It is seen from Fig. $2 \mathrm{~d}$ that individual effect of soaking time was maximum at level -1 for higher yield of xylose, and as the level was increased the yield decreased. This may be due to the fact that with the increasing soaking time there may be a saturation effect for weakening of the bonds present in the hemi-cellulose.

Now, it is clear from Fig. 2(a-d) that the optimum levels are: $\mathrm{A}_{2}$ (temperature: $130{ }^{\circ} \mathrm{C}$ ), $\mathrm{B}_{3}$ (concentration: 5\%), $\mathrm{C}_{3}$ (treatment time: $10 \mathrm{~min}$ ) and $\mathrm{D}_{1}$ (soaking time: $30 \mathrm{~min}$ ) respectively.

In addition to $\mathrm{S} / \mathrm{N}$ analysis, main effects of the process parameters on the mean response are also analyzed. The mean response refers to the average value of the quality characteristic for each factor at different levels. Thus the average values of the xylose yield for each factor at the three levels have been calculated and are plotted in Fig.3.

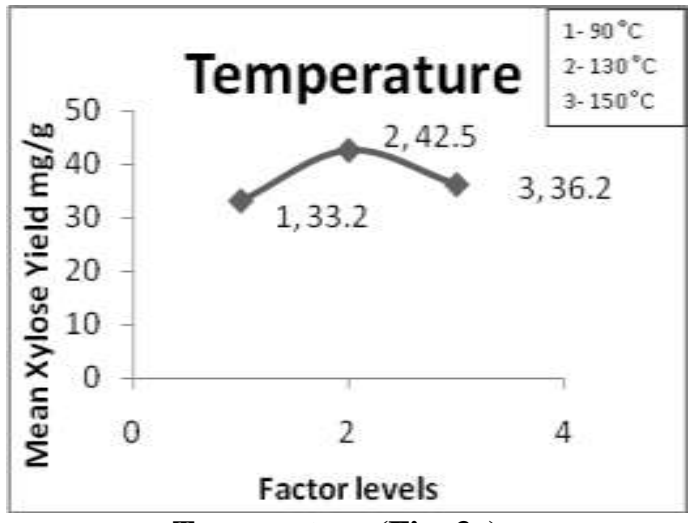

Temperature (Fig. 3a)

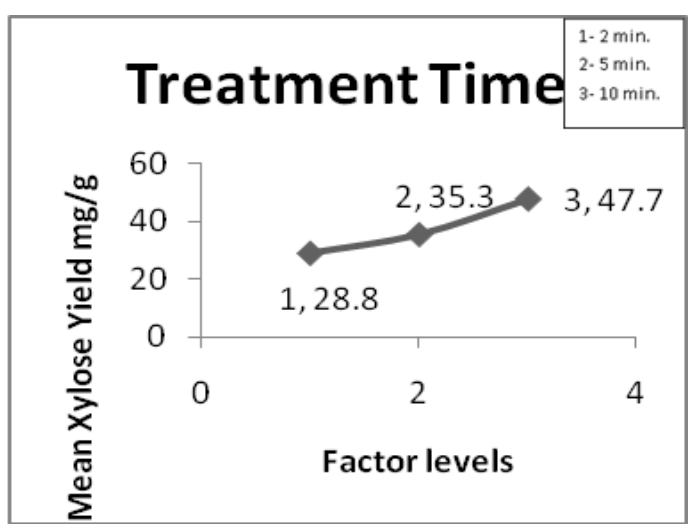

Treatment Time (Fig. 3c)

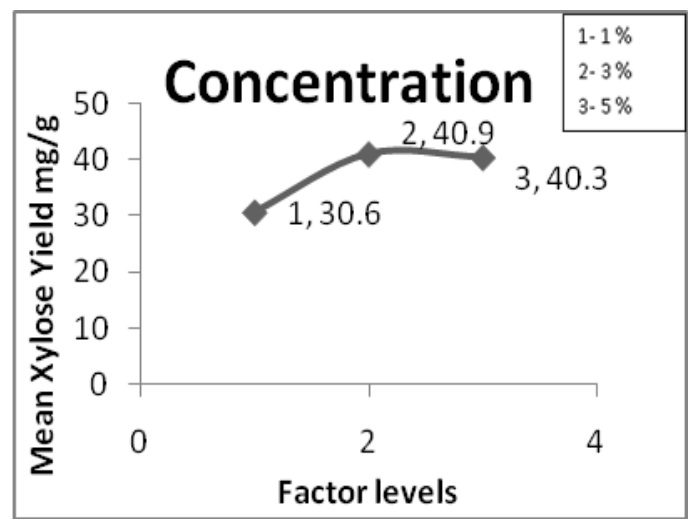

Concentration (Fig. 3b)

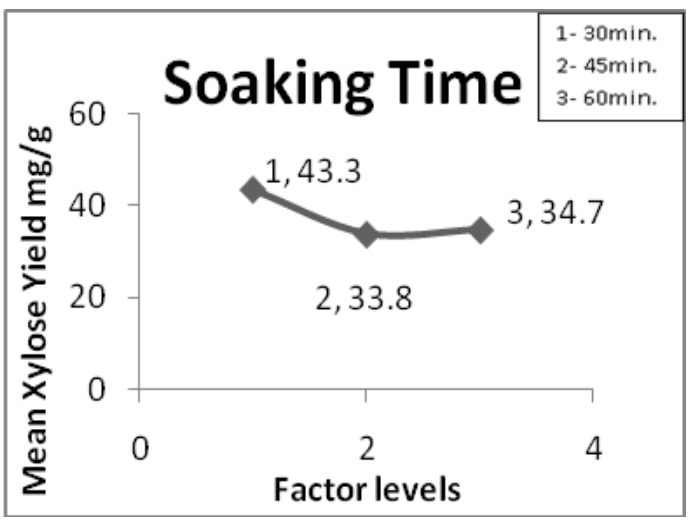

Soaking Time (Fig. 3d)

Fig. 3 Effects of process parameters on mean response characteristic

The mean response analysis (Fig. 3) indicates the optimum levels of the process parameters as $A_{2}, B_{2}$, $\mathrm{C}_{3}$, and $\mathrm{D}_{1}$ which is the same as obtained in $\mathrm{S} / \mathrm{N}$ ratio analysis except the concentration factor. However, both 
Optimization of Xylose yield from water hyacinth for ethanol production using Taguchi Technique the analysis of $\mathrm{S} / \mathrm{N}$ ratio and mean response characteristic reveal that relative difference between $\mathrm{B}_{2}$ and $\mathrm{B}_{3}$ is within $1.5 \%$.

The analysis of variance (ANOVA) was also performed to analyze the experimental data and to study the relative significance of the process parameters. Table 5 shows the computed results of the ANOVA with 95\% confidence. The F- ratio and the percent contributions of the various parameters as quantified under the respective columns of Table 5 reveal that all the parameters are statistically significant within $95 \%$ confidence level since their F- ratios are higher than the critical value (3.55). However, treatment time contributed the maximum impact $(51.25 \%)$ on xylose yield followed by concentration (18.68\%), soaking time (15.28\%), and temperature (12.4\%).

Table 5 Analysis of Variance (ANOVA) for Xylose yield

\begin{tabular}{|c|c|c|c|c|c|c|c|}
\hline Factor & $\begin{array}{l}\text { Sum } \\
\text { Squares }\end{array}$ & of & DOF & Variance & F-ratio & $\begin{array}{l}\text { Pure Sum } \\
\text { of } \\
\text { squares }\end{array}$ & $\begin{array}{l}\text { Percent } \\
\text { contribution } \\
(\%)\end{array}$ \\
\hline Temp. & 404.862 & & 2 & 202.431 & $68.555^{*}$ & 398.957 & 12.4 \\
\hline Conc. & 606.553 & & 2 & 303.277 & $102.707 *$ & 600.648 & 18.68 \\
\hline $\begin{array}{l}\text { Treatment } \\
\text { Time }\end{array}$ & 1654.16 & & 2 & 827.081 & $280.098^{*}$ & 1648.256 & 51.25 \\
\hline $\begin{array}{l}\text { Soaking } \\
\text { time }\end{array}$ & 497.497 & & 2 & 248.749 & $84.241^{*}$ & 491.592 & 15.28 \\
\hline $\begin{array}{l}\text { Other } \\
\text { errors }\end{array}$ & 53.158 & & 18 & 2.953 & & 76.773 & 2.386 \\
\hline Total & 3216.23 & & 26 & & & 3216.225 & 100 \\
\hline
\end{tabular}

Tabulated F-ratio at $95 \%$ confidence level: $\mathrm{F}(0.05,2,18)=3.55 ; *$ Significant at $95 \%$ confidence level.

\subsection{Prediction of optimum quality characteristic (QC)}

From the analyses of $\mathrm{S} / \mathrm{N}$ ratio and the mean response characteristic, the optimum levels of the control factors are determined respectively as: $\left(A_{2}, B_{3}, C_{3}, D_{1}\right) \&\left(A_{2}, B_{2}, C_{3}, D_{1}\right)$. However, $B_{2} \& B_{3}$ being close the predicted mean of optimum yield of xylose has been computed based on the $\mathrm{S} / \mathrm{N}$ ratio analysis [12].

$X_{m p}=\bar{Y}+\left(\overline{A_{2}}-\bar{Y}\right)+\left(\overline{B_{3}}-\bar{Y}\right)+\left(\overline{C_{3}}-\bar{Y}\right)+\left(\overline{D_{1}}-\bar{Y}\right)$

Where $\bar{Y}$ is the grand average of performance characteristic [corresponding to all the $27(=9 \times 3)$ readings in Table 3. $\overline{\mathbf{A}}_{2}, \overline{\mathbf{B}}_{3}, \overline{\mathrm{C}}_{3}$, and $\overline{\mathbf{D}}_{1}$ are the average values of the xylose yield with process parameters at their respective optimal levels and $X_{m p}$ denotes the predicted mean of the xylose yield at optimum condition. The calculated values of various response averages are: $\overline{\mathbf{Y}}=37.326 \mathrm{mg} \mathrm{g}^{-1}, \overline{\mathbf{A}}_{2}=42.522 \mathrm{mg} \mathrm{g}^{-1}, \overline{\mathbf{B}}_{3}=40.38 \mathrm{mg} \mathrm{g}$ ${ }_{1}, \overline{\mathbf{C}}_{3}=47.739 \mathrm{mg} \mathrm{g}^{-1}$, and $\overline{\mathrm{D}}_{1}=43.373 \mathrm{mg} \mathrm{g}^{-1}$. So substituting these in Equation 2 , the mean optimum value of the xylose yield has been predicted as: $\mathrm{X}_{\mathrm{mp}}=62.04$.

An important step in Taguchi's optimization technique is to conduct confirmation experiments for validating the predicted results. Thus a 95\% confidence interval (CI) for the predicted mean of optimum QC on a confirmation test is estimated using the following two equations [12]:

$$
C I=\sqrt{F\left(\alpha, 1, f_{e}\right) V_{e}\left[\frac{1}{N_{e f f}}+\frac{1}{R}\right]------(3)}
$$

and

$$
N_{e f f}=\frac{N}{1+T_{D O F}}-----(4)
$$

where, $F\left(\alpha, 1, f_{e}\right)$ is the F-ratio required for $100(1-\alpha)$ percent confidence interval, $f_{e}$ is DOF(degrees of freedom) for error, $\mathrm{V}_{\mathrm{e}}$ is the error variance, $\mathrm{R}$ is number of replications for confirmation experiment $(=3)$, and 
Optimization of Xylose yield from water hyacinth for ethanol production using Taguchi Technique

$\mathrm{N}_{\text {eff }}$ is effective number of replications. $\mathrm{N}$ is total number of experiments [= $\left.27(9 \times 3)\right]$ and $\mathrm{T}_{\mathrm{DOF}}$ is the total degrees of freedom $[=8(2 \times 4)]$ associated with the estimate of mean optimum. From Table 5, the values are: $\mathrm{V}_{\mathrm{e}}=2.953, \mathrm{f}_{\mathrm{e}}=18$, and from standard Statistical Table, the required F-ratio for $\alpha=0.05$ is: $\mathrm{F}(0.05,1,18)=$ 4.41. Substituting these values in Equations 3 and 4, the calculated confidence interval is: $\mathrm{CI}= \pm 2.95$. Thus the $95 \%$ confidence interval of the predicted optimal xylose yield is obtained as: $(62.04 \pm 2.95) \mathrm{mg} \mathrm{g}^{-1}$ i.e. $59.09<$ $\mathrm{X}_{\mathrm{mp}}\left(\mathrm{mg} \mathrm{g}^{-1}\right)<64.99$

\subsection{Confirmation experiment}

In order to test the predicted result, confirmation experiment has been conducted by running another three replications at the optimal settings of the process parameters determined from the analysis. These results are shown in Table 6 and it is observed that the mean xylose yield obtained from the confirmation experiments is $65.03 \mathrm{mg} \mathrm{g}^{-1}$, which falls almost within the predicted $95 \%$ confidence interval.

Table 6 Results of Confirmation Experiment

\begin{tabular}{|c|c|c|c|c|c|}
\hline \multicolumn{5}{|c|}{ Replications } & \multirow{2}{*}{ Mean } \\
\hline & & Reading 1 & Reading 2 & Reading 3 & \\
\hline $\begin{array}{l}\text { Xylose } \\
(\mathrm{mg} / \mathrm{g})\end{array}$ & yield & 65.65 & 65.03 & 64.4 & 65.03 \\
\hline
\end{tabular}

Optimum combination of control factors for confirmation experiment: Temperature: $130^{\circ} \mathrm{C}$; Concentration: 5\%; Treatment time: $10 \mathrm{~min}$; Soaking Time: $30 \mathrm{~min}$; 95\% confidence interval of predicted xylose yield: $(62.04 \pm 2.95) \mathrm{mg} \mathrm{g}^{-1}$.

\subsection{Correlation}

The yield of xylose on hydrolysing water hyacinth with sulphuric acid has been studied against treatment temperature, concentration of acid, treatment time and soaking time. The experimental data obtained have been correlated by the following two expressions using multiple regression technique are shown in Fig.4.

$\mathrm{Y}=\mathrm{a}_{1}+\mathrm{a}_{2} \mathrm{~T}+\mathrm{a}_{3} \mathrm{C}^{2}+\mathrm{a}_{4} \mathrm{t}_{\mathrm{t}}{ }^{3}+\mathrm{a}_{5} \mathrm{t}_{\mathrm{s}}{ }^{4}$

$\left(\mathrm{a} 1=20.6873, \mathrm{a}_{2}=0.0759, \mathrm{a}_{3}=0.3429, \mathrm{a}_{4}=0.0172, \mathrm{a}_{5}=-0.0000\right)$

$\mathrm{Y}=\mathrm{a}_{1}+\mathrm{a}_{2} \operatorname{Sin}\left(\mathrm{a}_{3} \mathrm{~T}\right)+\mathrm{a}_{4} \operatorname{Sin}\left(\mathrm{a}_{5} \mathrm{C}\right)+\mathrm{a}_{6} \operatorname{Sin}\left(\mathrm{a}_{7} \mathrm{t}_{\mathrm{t}}\right)+\mathrm{a}_{8} \operatorname{Sin}\left(\mathrm{a}_{9} \mathrm{t}_{\mathrm{s}}\right)$

$\left(a_{1}=-81.9401, a_{2}=-112.8541, a_{3}=0.9553, a_{4}=19.0317, a_{5}=-3.5441, a_{6}=12.0713, a_{7}=-0.5552, a_{8}=-6.4502\right.$, $\left.\mathrm{a}_{9}=0.9888\right)$

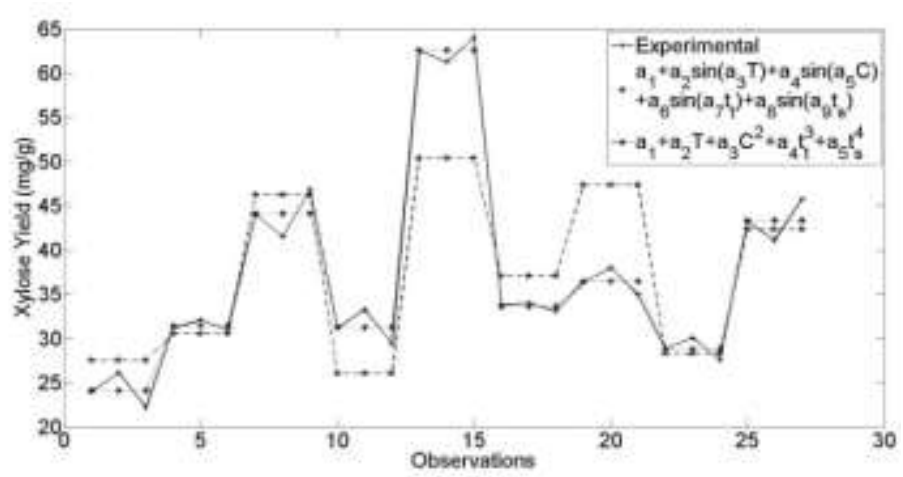

Fig. 4 Correlation of xylose yield with process variables

\section{CONCLUSION}

Optimization of process parameters namely temperature, treatment time, acid concentration and soaking time for xylose yield were performed employing Taguchi's parameter design method. The following conclusions may be drawn from the present investigation: The treatment time was having the highest contribution towards xylose yield to the order of $51.25 \%$. From confirmation experiments, the mean value of the xylose yield corresponding to the optimum conditions was obtained as $65.03 \mathrm{mg} \mathrm{g}^{-1}$, which is close to the predicted range. Two correlations have been developed from the experimental data based on multiple regression technique to predict the xylose yield.

\section{ACKNOWLEDGEMENT}

The authors are grateful to Director, CSIR-Central Mechanical Engineering Research Institute, Durgapur for constant support, encouragement and permission to publish this paper. 


\section{References}

[1] Nigam JN. Bioconversion of water-hyacinth (Eichhornia crassipes) hemicellulose acid hydrolysate to motor fuel ethanol by xylosefermenting yeast. J Biotechnol, 97, 2002, 107-116.

[2] Shonnard DR. Applications of Molecular Biotechnology Ethanol Production from Cellulosic Biomass. Biochemical Processes. USA: Michigan Technological University; 2003.

[3] Purwadi R, Niklasson C, Taherzadeh MJ. Kinetic study of detoxification of dilute-acid hydrolyzates by $\mathrm{Ca}(\mathrm{OH})_{2}$. J Biotechnol, 114 , 2004, 187-198.

[4] Saha BC, Lten LB, Cotta MA, Wu YV. Dilute acid pretreatment, enzymatic saccharification, and fermentation of wheat straw to ethanol. Proc Biochem, 40, 2005, 3693-3700.

[5] Dehnad K. Quality control, robust design, and the Taguchi method. CA: Wadsworth and Brooks: Pacific Grove; 1989.

[6] Bhunia B, Dutta D, Chaudhuri S. Selection of Suitable Carbon, Nitrogen and Sulphate Source for the Production of Alkaline Protease by Bacillus licheniformis NCIM-2042. Not Sci Biol, 2010;2:56.

[7] Chauhan B, Gupta R. Application of statistical experimental design for optimization of alkaline protease production from Bacillus sp. RGR-14. Process Biochem, 39, 2004, 2115-2122.

[8] Bhunia B, Dutta D, Chaudhuri S. Selection of Suitable Carbon, Nitrogen and Sulphate Source for the Production of Alkaline Protease by Bacillus licheniformis NCIM-2042. Not Sci Biol 2010;2:56.

[9] Montgomery DC. Design and analysis of experiments. $4^{\text {th }}$ ed. New york: John Wiley; 1997.

[10] Elberts TJ, Sample RH, Glick MR, Ellis GH. A simplified, colorimetric micro method for xylose in serum or urine, with phloroglucinol. Clin Chem, 25, 1979, 1440-1443.

[11] Johnson SL, Bliss M, Mayersohn KA. Phloroglucinol-based colorimetry of xylose in plasma and urine compared with a specific gas-chromatographic procedure. Clin Chem,;30, 1984, 1571-1574.

[12] Singh H, Kumar P. Tool wear optimization in turning operation by Taguchi method. Indian journal of engineering and material science, 11,2004, 19-24. 